\title{
In-Situ Monitoring of Local Corrosion Process of Scratched Epoxy Coated Carbon Steel in Simulated Pore Solution Containing Varying percentage of Chloride ions by Localized Electrochemical Impedance Spectroscopy ${ }^{\bigotimes}$
}

\author{
T. Balusamy and T. Nishimura* \\ Research Center for Strategic Materials, Materials Recycling Design Group, \\ National Institute for Materials Science, Ibaraki, Tsukuba, 305-0047, Japan.
}

\begin{abstract}
The present work focuses on the corrosion behaviour of scratched epoxy coated carbon steel in simulated pore solution (SPS) containing varying \% of chloride ions (added as $\mathrm{NaCl}$ ) by localized electrochemical impedance spectroscopy (LEIS). LEIS results indicate that the $|\mathrm{Z}|$ at the scratch is decreased significantly with an increase in $\%$ of $\mathrm{Cl}^{-}$ions in SPS, which is evidenced by the formation of a depressed semicircle in the LEIS Nyquist plots. The intermediate corrosion products involved in the local corrosion process appears to be a function of the $\%$ of $\mathrm{Cl}^{-}$ions present in SPS. The competition between the aggressive $\mathrm{Cl}^{-}$ions and the inhibitive $\mathrm{OH}^{-}$ions and the extent of decrease in $\mathrm{pH}$ at interface determines the rate of corrosion. The LEIS maps acquired at $10 \mathrm{~Hz}$ provides a better understanding of the involvement of the anodic and cathodic areas on the local corrosion process of scratched epoxy coated carbon steel. The continuous decrease in $|\mathrm{Z}|$ at the scratch is due to the higher extent of dissolution of $\mathrm{Fe}$ at the scratch while the change in $|\mathrm{Z}|$ over the coating is determined by the extent of dissolution of $\mathrm{Fe}$ and accumulation of corrosion products over the coating due to the high bulk $\mathrm{pH}$ of SPS. No significant decrease in $|\mathrm{Z}|$ at the scratch is observed when the $\%$ of $\mathrm{Cl}^{-}$ions in SPS is 0.05 . However, when the $\%$ of $\mathrm{Cl}^{-}$ions in SPS is increased beyond $0.05 \%$, a significant increase in the corrosion rate of scratched epoxy coated carbon steel is observed. Hence, $0.05 \% \mathrm{NaCl}$ can be considered as a threshold level of chloride ions in SPS. A pictorial model is proposed to explain the local corrosion process and mechanism of scratched epoxy coated carbon steel in chloride containing SPS.
\end{abstract}

Key words: Scratched Epoxy coating; corrosion; localized electrochemical impedance spectroscopy (LEIS); simulated pore solution (SPS); chloride;

*Corresponding author. E-mail: NISHIMURA.Toshiyasu@,nims.go.jp

${ }^{\text {\# }}$ Presented at the $66^{\text {th }}$ Annual Meeting of International Society of Electrochemistry held at TICC-Taipei, Taiwan, during October 4-9, 2015.

(Best poster prize was awarded for this work) 


\section{Introduction}

Electrochemical impedance spectroscopy (EIS) has long been used to evaluate ability of coatings to resist corrosion of metals/alloys. The shape of the curves in the Nyquist plot, number of inflections and the $|\mathrm{Z}|$ in the Bode impedance plot and, phase angle maximum as well as the frequency at which the phase angle reaches a maximum in the Bode phase angle plots helps to understand the mechanism of corrosion of coated steel by EIS $[1,2]$. However, the major limitation of this method is its inadequacy since the measured impedance values correspond to the electrochemical response of the whole electrode and it fails to reflect the averaged behavior of the macroscopic electrode having pinholes/defects. Hence, it is very difficult to extract complete quantitative information about the initial stages of corrosion and coating degradation.

In recent years, local electrochemical impedance spectroscopy (LEIS) technique has been widely used to study localized corrosion of uncoated/coated metal systems at microscopic level [3-12]. Philippe et al. [8] have studied the degradation of polyester coil-coated galvanized steel with $250 \mu \mathrm{m}$ diameter artificial defect in $\mathrm{NaCl}$ by LEIS as well as conventional EIS at different time intervals. The LEIS could effectively separate the local impedance properties of the organic coating with defect when compared to the conventional EIS, which always provides surface averaged results. Zou and Thierry [9] used LEIS technique to study the degradation of organic coatings on metals. It was found that LEIS could be used to detect the onset of blistering and gave a measure of the rate of diffusion of water into the organic coating at a microscopic scale. Zhong et al. [10] have studied corrosion of steel under the defected coating ( 200 and $1000 \mu \mathrm{m}$ diameter in near-neutral $\mathrm{pH}$ solution using LEIS. According to them, the LEIS 
response was dependent on the size of the defect. It was found that the $200 \mu \mathrm{m}$ diameter was lost due to the blocking effect, which was mainly dominated by the diffusion process. On the other hand, the blocking effect was not experienced in the $1000 \mu \mathrm{m}$ defect due to its relatively open geometry. Jorcin et al. [6] have explored the use of LEIS mapping to assess the delamination phenomena at the steel/epoxy-vinyl primer interface in $\mathrm{NaCl}$ and identified that the delamination has originated from the artificial defects. It has also been established that the increase in local $\mathrm{pH}$ propagates the delamination significantly in the steel-coating interface. The corrosion products formed at the defect acts as anodic zones, which hinders the transport of $\mathrm{O}_{2}$ at this defect site and favors the reduction of $\mathrm{O}_{2}$ at cathodic sites, especially over the coated area, which in turn promotes cathodic delamination at the steel-coating interface. Hence, LEIS is a promising alternative technique to explore the corrosion mechanism of coatings with defects at microscopic level to understand their degradation behaviour as well as the localized corrosion behaviour of steel in simulated pore solution (SPS) containing chloride ions.

The threshold level of chloride ions in SPS is one of the critical factors that determine the corrosion behaviour of reinforcing steels in contact with concrete. Glass and Buenfeld [13] have reported that the total chloride content relative to the weight of cement was the best way to express the threshold level of chloride in concrete pore solution, at the same time the bound chloride at the steel-concrete interface is yet another important parameter that decides the corrosion mechanism of reinforcement steel. Shi et al. [14] have compared the modeling performed using artificial neural network (ANN) and the laboratory data to establish the correlation between the 
influential factors with the risk of pitting of steel. It was found that the complex interactions between various influencing factors on threshold level of chlorides to the steel rebar corrosion in SPS was a function of dissolved oxygen concentration, $\mathrm{pH}$ and chloride binding, and not a unique value. Angst et al. [15] have also reviewed many experimental results and could not arrive at any realistic results on the threshold level of chloride. Comparison of the reported values poses difficulty due to the differences in the procedures. Angst et al. [15] have suggested that potential measurements, linear polarization resistance, or EIS are appropriate methods rather than potentiodynamic or galvanostatic polarization studies. Since, most of previous measurements on the establishment of the threshold level of chloride for reinforcing steel corrosion were carried out only by the traditional electrochemical tests in the single component SPS, namely saturated $\mathrm{Ca}(\mathrm{OH})_{2}$ solution with the addition of chloride ions. Hence, in the present study, an attempt is made to understand the corrosion mechanism of scratched epoxy coated carbon steel in saturated $\mathrm{Ca}(\mathrm{OH})_{2}$ with varying $\%$ of $\mathrm{NaCl}$ by LEIS measurements. In addition, it is believed that LEIS and LEIS mapping could provide useful information about the corrosion mechanism of scratched epoxy coated carbon steel in SPS with varying \% of $\mathrm{NaCl}$. Moreover, the inferences made in this study are likely to provide a better understanding on the threshold level of chloride in a concrete pore solution.

\section{Experimental details}

\subsection{Preparation of specimens}

The chemical composition of the carbon steel specimens was 0.1C-0.3 Si-0.7Mn-0.01P-0.003S-0.03Al-0.003N- 0.002 O-balance Fe (in mass \%) as 
per JIS-SM (Japan industrial standard-sheet metal). The specimen, with a surface area of $1.7 \times 1.7 \mathrm{~cm}^{2}$, was polished using silicon carbide ( $\mathrm{SiC}$ ) papers upto 800 grit. After polishing, the samples surface were rinsed with distilled water and dried with compressed air, and cleaned with ethanol before coating.

\subsection{Preparation of coatings and electrolyte solution}

The organic coating used in this investigation was commercially available fast drying epoxy. The liquid epoxy resin was a blend of multifunctional low molecular weight diluents and the diglycedal ether of bis-phenol-A, whereas the curing agent was based on the aliphatic amines. The weight ratio of the epoxy resin to the curing agent was 2:1. The epoxy resin was coated using a drawdown bar at a constant speed and then kept at room temperature for $24 \mathrm{~h}$. This led to the formation of uniform coating with thickness of about $\sim 40 \mu \mathrm{m}$. After coating, an artificial scratch in the epoxy coating was produced by using a driller to produce a scratch of $1000 \mu \mathrm{m}$ width and length about $10 \mathrm{~mm}$. The samples were then exposed to aerated aqueous solutions of saturated $\mathrm{Ca}(\mathrm{OH})_{2}$ with varying \% of $\mathrm{NaCl}$, viz., $0.05,0.5,1$ and $3 \%$. Hereafter, saturated $\mathrm{Ca}(\mathrm{OH})_{2}$ and saturated $\mathrm{Ca}(\mathrm{OH})_{2}$ containing $0.05,0.5,1$ and $3 \% \mathrm{NaCl}$ will be referred as a $0,0.05,0.5,1$ and $3 \% \mathrm{Cl}$. The test electrolyte was prepared using analytical grade chemicals then filtered using Whatman 42 filter paper.

\subsection{LEIS measurements}

The LEIS measurements were performed using Model 470 scanning electrochemical work station, which comprises a Potentioste/Galvanostate/FRA (model 3300) with lock-in amplifier, environmental tri-cell system, a video microscope system 
to position the micro-probe over the working electrode (WE). The schematic of the electrode installation and experimental set-up of LEIS is shown in Fig. 1. Scratched epoxy coated carbon steel was a working electrode (WE) while saturated calomel electrode (SCE) and a graphite rod were used as the reference and auxiliary electrodes, respectively. The relative location of the microprobe to the WE was monitored by the camera system, which can be adjusted by a stepper motor in the $\mathrm{x}, \mathrm{y}, \mathrm{z}$ directions. The scanning microprobe was operated in two modes. The first mode was used for LEIS measurements. The microprobe having a 5-6 $\mu \mathrm{m}$ tip was set directly above the scratched epoxy coated carbon steel to measure the typical impedance response. The distance between the tip of the microprobe and the surface of the WE was $\sim 50 \mu \mathrm{m}$, which was adjusted and monitored with the help of a video camera TV system, supplied along with the workstation. During LEIS measurements, an AC amplitude signal of $50 \mathrm{mV}$ was applied to the electrode system. The frequency range used for the study was 20,000 to 0.1 Hz. The electrochemical parameters were derived from the LEIS data after fitting them using ZSimpWin 3.21 software. The second mode was used for LEIS mapping at a fixed frequency of $10 \mathrm{~Hz}$. The tip of the microprobe was stepped over a designated area of the electrode surface. The scanning was performed by the moving of the tip of the microprobe in the $x-y$ axis while the $x-y$ scales were set as a $7 \times 1 \mathrm{~mm}$. The step size (100 x $200 \mu \mathrm{m}$ in $\mathrm{x}-\mathrm{y}$ direction) was controlled to obtain a plot of 71 lines $\mathrm{x} 6$ lines. The 3D and 2D plots were obtained from 3DIsoplot software. Specimens were mounted horizontally facing upwards. Before all experiments, the scratched epoxy coated carbon steels (WE) was kept at open-circuit potential (OCP) in the test solution for $1800 \mathrm{~s}$ and LEIS measurements were made at their respective OCP's. 


\section{Results and discussion}

\subsection{OCP-time measurements}

The change in OCP-time measurements performed before LEIS measurements is shown in Fig. 2. It is evident that, in the absence of $\mathrm{Cl}^{-}$ions in the SPS, the free corrosion potential of the scratched epoxy coated steel is around $-0.12 \mathrm{~V}_{\mathrm{SCE}}$. Addition of $\mathrm{Cl}^{-}$ions in the SPS has led to a shift in OCP in the negative direction and the extent of shift in OCP becomes much higher (from -0.25 to $-0.54 \mathrm{~V}_{\mathrm{SCE}}$ ) with an increase in the concentration of $\mathrm{Cl}^{-}$ions (from 0.05 to $3 \%$ ) in the SPS. This clearly indicates the dependence of the OCP with the $\mathrm{Cl}^{-}$ion concentrations in SPS. The fluctuations in the OCP-time curve obtained in SPS containing $0.05 \%$ to $0.5 \% \mathrm{Cl}^{-}$could be attributed to the competition between adsorption of the aggressive $\mathrm{Cl}^{-}$ions and the inhibitive $\mathrm{OH}^{-}$ ions, thus inducing dissolution and passivation, respectively, during the corrosion process. In general, when a metal is immersed in an electrolyte, the current density in the electrical double layer (metal/electrolyte interface) leads to charging/discharging of capacitance as $\mathrm{C}=\mathrm{q} / \mathrm{V}$, where $\mathrm{q}$ is the charge build up in double layer during metal dissolution and $\mathrm{V}$ is free corrosion potential of the metal. Moreover, if a passive film grows on the electrode surface (coverage of film on the electrode surface), then it could lead to a decrease in micro-pores present in passive film and metal dissolution. This ultimately decreases the initial exposed area of the electrode surface. Hence, double layer capacitance is likely to decrease. In the present study, the LEIS measurement is performed in SPS containing varying $\%$ of $\mathrm{Cl}^{-}$ions after OCP-time measurements.

\subsection{LEIS measurements performed at scratched epoxy coated carbon steel}

LEIS measurements performed on scratched epoxy coated carbon steel in SPS 
containing $0,0.05,0.5,1$ and $3 \%$ of $\mathrm{Cl}^{-}$ions. LEIS Nyquist plots of scratched epoxy coated carbon steel in SPS containing varying $\% \mathrm{Cl}^{-}$ions are shown in Fig. 3. The corresponding Bode impedance and Bode phase angle plots are shown in Fig. 4. It is evident from Fig. 3 that the capacitive part at high frequency range is associated with the coating impedance with scratch, the inductive loop at intermediate frequencies is due to the adsorption of corrosion species involved in the local corrosion process and, the capacitive part in the low frequency region is related to the double layer capacitance and charge-transfer resistance $[16,17]$. The obtained LEIS data is approximated using different equivalent electrical circuit models built in and analyzed using ZSimpWin 3.21 software and the most suitable model is selected on the basis of best fitting (the smallest Chi-Square values). The validity of the proposed model is confirmed based on the better non-linear least square fitting of the experimental data. The proposed electrical circuit model and the fittings obtained for the data points for all cases are shown in inset of Fig. 3(a). In this model, $R_{s}$ represents the solution resistance while $R_{f}$ and $C_{P E}$ correspond to the coating resistance with scratch and the corresponding coating capacitance, respectively. The $\mathrm{R}_{\mathrm{L}}$ and $\mathrm{L}$ are the inductive resistance and inductance of adsorbed intermediate corrosive species involved in the local corrosion process while $\mathrm{R}_{\mathrm{ct}}$ and $\mathrm{CPE}_{\mathrm{dl}}$ are the charge transfer resistance and double layer capacitance of the system, respectively. The impedance of CPE is given by $Z_{C P E}=1 / Q(j \omega)^{n}$, Where ' $n$ ' is the CPE exponent. The capacitance element $Q(C P E)$ will be pure capacitance when $\mathrm{n}=1$ while it will be pure resistance when $\mathrm{n}=0 . Q$ is called as $C P E$ when $0.5<\mathrm{n}<1$ and it prevails under conditions of surface heterogeneity. The electrochemical parameters derived after fitting the LEIS data are shown in Fig. 5. Since the value of ' $n$ ' lies between 0.60 and 0.98 in SPS and with varying $\% \mathrm{Cl}^{-}$ions, the choice of $\mathrm{CPE}$ as the 
circuit element seems to be appropriate. The observed impedance for scratched epoxy coated carbon steel is decreased with an increase in $\%$ of $\mathrm{Cl}^{-}$ions in SPS (Fig. 5a). This is clearly indicated by the depressed semicircles (Fig. 3a) with an increase in $\%$ of $\mathrm{Cl}^{-}$ ions in SPS. The coating resistance of scratched epoxy coated carbon steel is decreased from $4.64 \times 10^{6}$ to $1.76 \times 10^{5} \mathrm{ohm} . \mathrm{cm}^{2}$ and the charge transfer resistance from $6.90 \times 10^{6}$ to $3.80 \times 10^{6} \mathrm{ohm} . \mathrm{cm}^{2}$ with an increase in $\%$ of $\mathrm{Cl}^{-}$ions in SPS respectively. However, the corrosion behavior of the coated steel in SPS containing $0.05 \% \mathrm{Cl}^{-}$ions is comparable with that of the one in the absence of $\mathrm{Cl}^{-}$ions. The coating resistance with scratch $\left(\mathrm{R}_{\mathrm{f}}=4.64 \times 10^{6} \mathrm{ohm} . \mathrm{cm}^{2}\right)$ and the charge transfer resistance $\left(\mathrm{R}_{\mathrm{ct}}=6.90 \times 10^{6}\right.$ ohm. $\mathrm{cm}^{2}$ ) in the absence of $\mathrm{Cl}^{-}$ions in SPS are comparable with those obtained in SPS containing $0.05 \% \mathrm{Cl}^{-}$ions $\left(\mathrm{R}_{\mathrm{f}}=4.12 \times 10^{6}\right.$ and $\left.\mathrm{R}_{\mathrm{ct}}=6.54 \times 10^{6} \mathrm{ohm} \cdot \mathrm{cm}^{2}\right)$. Moreover, there is a notable change at intermediate frequencies; the inductive loop becomes larger for SPS containing 1 and 3\% $\mathrm{Cl}^{-}$ions (enlarged Fig. $3 \mathrm{~b}$ and c) when compared to others. This clearly indicates that the higher intermediate corrosion products due to corrosion reaction (i.e., dissolution of $\mathrm{Fe}$ ) was higher at the interface, thus increases the adsorption of corrosion products on the electrode surface as compared to others [16-18]. It is evident from Fig. 5(c) that the inductive resistance, $\mathrm{R}_{\mathrm{L}}$ is decreased from $3.75 \times 10^{6}$ to $7.95 \times 10^{4} \mathrm{ohm} . \mathrm{cm}^{2}$ and the inductance, $\mathrm{L}$ is decreased from $4.89 \times 10^{6}$ to $1.44 \times 10^{5}$ Henri with an increase in $\%$ of $\mathrm{Cl}^{-}$ions in SPS. A comparable inductive resistance and inductance are observed for SPS in the absence of $\mathrm{Cl}^{-}$ions and those containing $0.05 \%$ of $\mathrm{Cl}^{-}$ions, which clearly indicate that the corrosion behavior of scratched epoxy coated carbon steel does not change much if the $\%$ of $\mathrm{Cl}^{-}$ions in SPS is about $0.05 \%$. This is mainly attributed to the inhibitive ability of the $\mathrm{OH}^{-}$ions at the interface, which helps to form a better passive film. The presence of a higher $\%$ of $\mathrm{Cl}^{-}$ions $(1$ and $3 \% \mathrm{Cl})$ in SPS, 
promotes preferential adsorption of $\mathrm{Cl}^{-}$ions on the electrode surface and enhances the corrosion rate $[19,20]$. In the presence of higher $\%$ of $\mathrm{Cl}^{-}$ions, which produces fairly soluble hydrated ferrous chloride or hydroxy chlorides at the electrode surface interface initially that is later converted to the iron oxides have been reported [6]. Moreover, the formation of intermediate corrosion products $\left(\mathrm{GR}\left(\mathrm{Cl}^{-}\right)\right.$; i.e. $\left.\mathrm{Fe}_{4}(\mathrm{OH})_{8} \mathrm{Cl}_{2} 2 \mathrm{H}_{2} \mathrm{O}\right)$ on the steel in SPS containing $\mathrm{Cl}^{-}$ions have been also reported and confirmed earlier [21, 22]. According to them, the initial intermediate corrosion reactions on steel surface in $\mathrm{Cl}^{-}$ ions containing SPS media, which is given in equation (1) [22]

$$
\mathrm{Be} \rightarrow \mathrm{Fe}(\mathrm{OH})_{\mathrm{s}} \text { and }\left(\mathrm{GR}\left(\mathrm{Cl}^{-}\right)-4 \mathrm{FeOOH}\right.
$$

In the presence oxygen $\mathrm{GR}\left(\mathrm{Cl}^{-}\right)$could be easily converted to $\mathrm{FeOOH}$ according to the equation (2), due to the less stability of $\mathrm{GR}\left(\mathrm{Cl}^{-}\right)$.

$$
\begin{aligned}
& \mathrm{Fe}_{4}(\mathrm{OH})_{8} \mathrm{Cl} 2 \mathrm{H}_{2} \mathrm{O}\left(\mathrm{GR}\left(\mathrm{Cl}^{-}\right)\right)+3 / 4 \mathrm{O}_{2} \\
& -4 \mathrm{FeOOH}+\mathrm{Cl}^{-}+\mathrm{H}^{+}+\mathrm{Y}_{2} / \mathrm{H}_{2} \mathrm{O} \ldots \ldots \ldots \ldots \ldots \ldots \ldots \text { (2) }
\end{aligned}
$$

At the same time, presence of $\mathrm{Cl}^{-}$ions in a SPS, leads to the formation of $\mathrm{FeCl}_{2}$ probably hydrated $\mathrm{FeCl}_{2}$ at some locations not completely covering surface due to the preferential adsorption of $\mathrm{Cl}^{-}$ions, which could adsorb on more positive local sites [19]. Hence, it is believed that the formation of $\mathrm{Fe}(\mathrm{OH})_{2}$ and $\mathrm{FeCl}_{2}$ could have occurred at simultaneously, $\mathrm{GR}\left(\mathrm{Cl}^{-}\right)$could be formed via $\mathrm{Fe}(\mathrm{OH})_{2}$ then it converted to $\mathrm{FeOOH}$ in the presence of oxygen possibly mixed $(\gamma, \alpha$ and $\beta)$-FeOOH depending on various parameters such as temperature, dissolved oxygen concentration, $\mathrm{pH}, \mathrm{Cl}^{-}$ions concentration $[21,23]$. The release of $\mathrm{Cl}^{-}$and $\mathrm{H}^{+}$ions at the steel interface i.e., between $\mathrm{Fe}$ and $\mathrm{FeOOH}$ leads to the formation of soluble corrosion intermediate 
products, which enhances the action of local corrosion process auto-catalytically. The formation $\mathrm{H}^{+}$ions at the interface of $\mathrm{Fe}-\mathrm{FeOOH}$ are likely to decrease the $\mathrm{pH}$. Further, it has been reported that the decrease in $\mathrm{pH}$ with time in $\mathrm{Cl}^{-}$ions containing pore solution. The decrease in $\mathrm{pH}$ measure (not less than $11.5 \mathrm{pH}$ ) in situ at the steel/concrete interface is high at beginning. However, with the neutralization of the basic environment in concrete by the $\mathrm{OH}-$ and $\mathrm{H}+$ diffusion, the decrease of $\mathrm{pH}$ became slow. When the $\mathrm{Cl}^{-}$ ion concentration is increased, a decrease in $\mathrm{pH}$ could be observed at steel/concrete interface [24]. Hence, the small scratch in epoxy coating on steel could possibly lead to a decrease in $\mathrm{pH}$ during the local corrosion process. The formation of intermediate corrosive spices such as $\mathrm{Fe}(\mathrm{II})_{\mathrm{ad}}$ on steel surface play a self catalytic role in the corrosion process of steel have been also reported [17]. According to them, the corrosion product deposit on electrode surface enhances the anodic dissolution of the steel due to the adsorption of the intermediate species which induce self-catalytic mechanism for corrosion of steel in near-neutral $\mathrm{pH}$ solution. The formation higher intermediate species at higher $\% \mathrm{Cl}^{-}$ions in the present study (shown in Fig. 3c) confirms this phenomenon that the bigger inductive loops at intermediate frequency which indicate the dissolution of steel at the scratch area. In the present study, at $0.5 \%$ $\mathrm{Cl}(0.09 \mathrm{M})$ in a SPS solution, a significant decrease in impedance could be observed due to the concentration of $\mathrm{Cl}^{-}$ions. In such case, the concentration of $0.5 \% \mathrm{Cl}^{-}$ions $(0.09 \mathrm{M})$ vs $\mathrm{OH}^{-}$ions $(0.1 \mathrm{M})$ is more or less equal. However, $\mathrm{Cl}^{-}$ions take advantage to preferentially adsorb on the electrode surface leading to the formation of $\mathrm{FeCl}_{2}$ at more positive locations. The $\mathrm{Cl}^{-}$ions below $0.5 \% \mathrm{Cl}$ leads to the formation of $\mathrm{Fe}(\mathrm{OH})_{2}$ due to the inhibitive $\mathrm{OH}^{-}$ions which could further transformed to the $\mathrm{GR}\left(\mathrm{Cl}^{-}\right)$, finally leads to the formation of $\mathrm{FeOOH}$ easily at the steel surface in presence of dissolved oxygen. 
Hence, the formation of passive film could not be affected much at below $0.5 \%$ of $\mathrm{Cl}$ ions. In the present study chloride threshold level could be $0.05 \%$ since the impedance starts to decrease slightly as compared to SPS without containing $\mathrm{Cl}^{-}$ions. It has been reported that the $0.02 \% \mathrm{Cl}$ addition to the sat. $\mathrm{Ca}(\mathrm{OH})_{2}$ solution has no appreciable change in anodic behavior of steel and it was observed that $\mathrm{Cl}^{-}$ion concentration equal to or higher than $0.05 \%$ induce pitting of the steel [25]. Further, in case of potential measurements of steel vs. SCE in concrete/pore solution containing $\mathrm{Cl}^{-}$ions, $>-0.22 \mathrm{~V}$ passive; -0.22 to $-0.27 \mathrm{~V}$ active or passive; $<-0.27 \mathrm{~V}$ active have been reported $[26,27]$. Hence, the present study shows that $-0.12 \mathrm{~V}$ (SCE) for SPS is in passive state, in the presence $0.05 \% \mathrm{Cl}$ in to SPS, free corrosion potentials shifts to negative direction not exceeded $-0.25 \mathrm{~V}$ (SCE) which is active and passive state could be observed. While increasing $\% \mathrm{Cl}$ ions leads to the more negative shift of free corrosion potential from -0.25 to $-0.54 \mathrm{~V}(\mathrm{SCE})$ which is more active in higher $\% \mathrm{Cl}$ ions. The results observed from the present study indicate that the critical chloride level $\left(\mathrm{Cl}^{-}\right)$in SPS is $0.05 \%$ and above this threshold level, the local corrosion process increases significantly.

Numerous studies were made previously to identify the threshold level of $\mathrm{Cl}^{-}$ ions in SPS in terms of total chloride level, chloride to hydroxyl concentration ratio, free chloride concentration and chloride binding and hydroxyl concentration on the pitting and repassivation of steel [13-15, 28-32]. However, there is no unique value of chloride threshold level in a pore solution due to the differences in procedures adopted. Moreover, the dependence of the corrosion rate on dissolved oxygen, $\mathrm{pH}$ and chloride binding makes it more complex [14]. The present study identifies that the threshold level of $\mathrm{Cl}^{-}$ions in SPS is $0.05 \%\left(8.5 \times 10^{-3} \mathrm{M}\right)$ and above this threshold level, the 
corrosion rate is increased significantly. Hence, it is clear that the threshold level of $\mathrm{Cl}^{-}$ ions is $0.05 \%$ and below this concentration, the passive film characteristics of the scratched epoxy coated carbon steel is not affected in SPS. Since LEIS involves measurement of impedance at a single point over the scratch or at the intermediate region or over the coating at a time, it provides a better understanding of the corrosion mechanism. The LEIS maps acquired at different zones of the same sample covering a large area is useful to get a better understanding of the rate of corrosion at these zones.

\subsection{LEIS mapping performed at scratched epoxy coated carbon steel}

For a better understanding of the mechanism of corrosion of scratched epoxy coated carbon steel in SPS containing varying $\%$ of $\mathrm{Cl}^{-}$ions, LEIS maps were acquired at a fixed frequency of $10 \mathrm{~Hz}$. The 3D LEIS maps and the corresponding 2D maps measured over a scanning area of $7 \mathrm{~mm} \times 1 \mathrm{~mm}$ (x-y scale) over the scratched epoxy coated carbon steel in SPS containing varying \% of $\mathrm{Cl}^{-}$ions are shown in Fig. 6. In Figs. 6 (a) to $6(\mathrm{e}),|\mathrm{Z}|$ represents the measured impedance (3-D impedance distribution along the $\mathrm{x}-\mathrm{y}$ axis) over the scratched epoxy coated carbon steel, which is an indicator of the electrode stability at various individual points. The magnitude of $|Z|$ is represented by different colour shades; blue, light blue, light green, dark green and red, in the order of increasing $|\mathrm{Z}|$ (Fig. 6). It is evident that the $|\mathrm{Z}|$ is high over the coating (represented as zone $\mathrm{H}$ ), moderate in the interfacial region between the coating and scratched area (represented as zone I) and low in the scratched area (represented as zone L). The average $|\mathrm{Z}|$ measured at zone $\mathrm{H}$ is $\sim 1 \times 10^{7} \mathrm{ohm} . \mathrm{cm}^{2}$ whereas it decreased to $\sim 7 \times 10^{6}$ ohm. $\mathrm{cm}^{2}$ in zone L in a SPS. Another interesting observation is the presence of an additional green color area near the scratch lines which spreads deep in to the $\mathrm{H}$ zone 
(marked by arrow marks in Fig. 6(f)). It indicates that the corrosion starts at selected points through the scratch lines due to the dominant cathodic reactions (cathodic delamination) near the scratch lines. Upon addition of $\mathrm{Cl}^{-}$ions to the SPS, the average IZ starts to decrease both at the $\mathrm{H}$ zone as well as at the $\mathrm{L}$ zone. This inference indicates that the local corrosion process is enhanced by the $\mathrm{Cl}^{-}$ions due to the likely reduction in local $\mathrm{pH}$ which produce soluble intermediate corrosion products. However, the addition of $\mathrm{Cl}^{-}$ions in SPS did not show any specific cathodic delamination areas near the scratch lines/over the coating, which may be due to the dominant anodic reactions rather than the cathodic reactions. This inference confirms that the penetration of $\mathrm{Cl}^{-}$ions through the scratch in the epoxy coating has induced anodic corrosion reaction rather than cathodic delamination.

The LEIS line profiles shown in Fig. 7(a), clearly indicate the decrease in $|Z|$ in the L-zone due to the higher dissolution of Fe at the scratched area. The $|\mathrm{Z}|$ measured at the $\mathrm{L}$ zone as a function of the $\%$ of $\mathrm{Cl}^{-}$ions in SPS is plotted in Fig. 7(b). It is evident from the Fig. 7 that an increase in $\%$ of $\mathrm{Cl}^{-}$ions in SPS has lead to an increase in the rate of corrosion of scratched epoxy coated steel in the $\mathrm{L}$ zone. The shape of the curves in Fig. 7(a) further confirms the inferences made from Fig. 6 that at higher $\%$ of $\mathrm{Cl}^{-}$ions, the extent dissolution of $\mathrm{Fe}$ at the scratched area becomes higher which provides a higher concentration of soluble $\mathrm{Fe}(\mathrm{II}) / \mathrm{Fe}$ (III) complex compounds near the interface of the scratched epoxy coated carbon steel. Further, the continuous decrease in $|\mathrm{Z}|$ over the coating and the scratched area indicates that a continuous dissolution of $\mathrm{Fe}$ and the easy availability of corrosive intermediate species (containing $\mathrm{Fe}(\mathrm{II}) / \mathrm{Fe}(\mathrm{III})$ compounds) near the scratched area which could be deposited over the coating. The decrease in $|Z|$ in the 
coated region may be due the deposition of the corrosion products over the coating, since the freely available soluble intermediate corrosive species in a solution (containing $\mathrm{Fe}(\mathrm{II}) / \mathrm{Fe}(\mathrm{III})$ compounds) that are moving during the scanning are likely to precipitate over the coating due to the higher $\mathrm{pH}$ from the bulk solution $[33,34]$. However, there is no sign of additional defects over the coating that has been observed from the LEIS maps with the addition of $\mathrm{Cl}^{-}$ions to the SPS. On the other hand, the decrease in $|\mathrm{Z}|$ over the coating might be due to the water uptake of the epoxy coating. Since the duration of the experiment is relatively less, the chances for the decrease in $|Z|$ due to water uptake or diffusion of the ions is less. Hence, the decrease in $|\mathrm{Z}|$ over the coating could be attributed to the deposition of corrosion products over the coating. At higher $\%$ of $\mathrm{Cl}^{-}$ions, fairly soluble ferrous chloride hydrate or hydroxy chlorides are formed initially, which then transform in to insoluble oxides by hydrolysis and further oxidation. The $\mathrm{Cl}^{-}$ions that are released during this process could again participate in producing soluble primary corrosion products, thus auto-catalytically promoting the localize corrosion reaction [17]. In addition, the formation of intermediate and final corrosion products depends on the $\mathrm{Cl}^{-}$ion concentration that determines the overall corrosion rate of the scratched epoxy coated carbon steel [34].

Based on the inferences made in the present study, a pictorial model is proposed to explain the corrosion mechanism of scratched epoxy coated carbon steel in SPS containing varying \% of $\mathrm{Cl}^{-}$ions (Fig. 8). Beyond the threshold level, the $\mathrm{Cl}^{-}$ions increased the dissolution kinetics of scratched epoxy coated carbon steel. As discussed earlier, the corrosion mechanism of scratched epoxy coated carbon steel in SPS is mainly due to the increased local $\mathrm{pH}$ (dominant cathodic reactions) in the scratch line 
front that leads to cathodic disbondment of coating (marked by red arrow marks in Fig. 8). The formation of $\mathrm{Fe}(\mathrm{OH})_{2}$ could be the initial corrosion product formed at scratch in SPS while at a later stage it is converted to $\mathrm{FeOOH}$ in the presence of dissolved oxygen [35] (Fig. 8 (a)). The formation of corrosion products hinder the transport $\mathrm{O}_{2}$ at the scratch, favors reduction of $\mathrm{O}_{2}$ at cathodic sites, especially in the scratch front as well as coated area, resulting in cathodic delamination due to the increase in $\mathrm{pH}$ (formation of $\mathrm{OH}^{-}$ions in the scratch front and at the steel-coating interface). In the presence of $\mathrm{Cl}^{-}$ions, some amount of $\mathrm{Fe}(\mathrm{OH})_{2}$ and $\mathrm{FeCl}_{2}$ is likely to form as corrosion products initially, which leads to the formation intermediate corrosion products $\left(\mathrm{GR}\left(\mathrm{Cl}^{-}\right)\right)$on the steel surface. The $\mathrm{GR}\left(\mathrm{Cl}^{-}\right)$could be converted easily to $(\gamma, \alpha$ and $\beta)-\mathrm{FeOOH}$ in the presence oxygen as final corrosion products. The type of corrosion products also depends on the $\mathrm{Cl}^{-}$ion concentration (Fig.8 (b)) [21-23, 34]. Moreover, the formation of intermediate corrosion products containing $\mathrm{Fe}(\mathrm{II}) / \mathrm{Fe}(\mathrm{III})$ compounds as a complex is probably cationic nature in a solution state due to the higher solubility, which migrates away from corroding steel, and it incorporates with hydroxyl ions in order to attain a reasonable neutrality [33]. It has been also reported that the oxidation of $\mathrm{Fe}^{2+}$ ions as intermediate corrosion products at the interface, it can be migrated several millimeters in the pore network before any precipitation [34]. This could be deposited over the

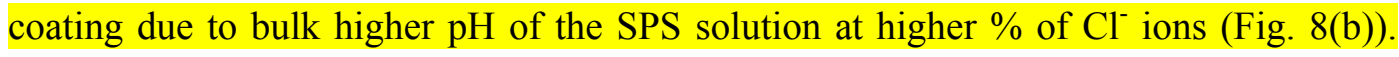
However, when the $\mathrm{Cl}^{-}$ions in SPS is $0.05 \%$, no significant change in impedance over the coating as well as over the scratched area could be observed (Figs. 3-7) and the corrosion behaviour is highly comparable what those observed in the absence of $\mathrm{Cl}^{-}$ions in SPS. This is due to the inhibitive ability of the $\mathrm{OH}^{-}$ions, which is sufficiently available for the formation of passive film at the scratched area more likely as a $\mathrm{FeOOH}$ 
$(\gamma$ and $\alpha$ ). Hence, there is no change in the characteristics of the passive film could be observed. However, with a further increase in $\%$ of $\mathrm{Cl}^{-}$ions in SPS, the $|\mathrm{Z}|$ decreased significantly. The cathodic delamination is the predominant process at high $\mathrm{pH}$ in the scratch line front, which is also a function of the $\mathrm{Cl}^{-}$ion concentration. The cathodic delamination at scratch line front and anodic reaction at the scratch could coexist at the same time. This implies that the corrosion mechanism is a complex process in the scratched area of the epoxy coated carbon steel and depends on the type of metal/alloy, its chemical composition and ability to form a passive film, defect size, concentration of $\mathrm{Cl}^{-}$ions, transport phenomena and the nature of corrosion products [36-38]. The experimental results of the present study as well as the LEIS maps provides a better insight on local corrosion mechanism of scratched epoxy coated carbon steel in SPS containing varying $\%$ of $\mathrm{Cl}^{-}$ions.

\section{Conclusion}

The effect of varying \% of chloride ions (added as $\mathrm{NaCl}$ ) on the local corrosion behaviour of scratched epoxy coated carbon steel in SPS is studied by LEIS. The change in $\mathrm{OCP}$ and $|\mathrm{Z}|$ clearly indicate that an increase in $\%$ of $\mathrm{NaCl}$ beyond $0.05 \%$ in SPS, leads to the significant increase in the corrosion rate of the scratched epoxy coated carbon steel. The intermediate corrosion products formed on the scratched epoxy coated carbon steel- $\mathrm{NaCl}$ interface and the final corrosion products depends on the competition between the aggressive $\mathrm{Cl}^{-}$ions and the inhibitive $\mathrm{OH}^{-}$ions. The release of $\mathrm{Cl}^{-}$and $\mathrm{H}^{+}$ ions at the steel interface i.e., between $\mathrm{Fe}$ and $\mathrm{FeOOH}$ leads to the formation of soluble corrosion intermediate products, which enhances the action of local corrosion process auto-catalytically and decreases the $\mathrm{pH}$. The $|\mathrm{Z}|$ measured by LEIS exhibits a continuous 
decrease at the scratch due to the higher dissolution of Fe with an increase in $\%$ of $\mathrm{Cl}^{-}$ ions in SPS, which is further validated by the variation in $|Z|$ by LEIS maps. The decrease in $|\mathrm{Z}|$ over the coating is mainly attributed to the deposition of intermediate corrosion products near the scratch rather than water induced adhesion loss during the local corrosion of the scratched epoxy coated carbon steel. Further, LEIS maps acquired at $10 \mathrm{~Hz}$ provides a better reorganization of anodic and cathodic areas during the corrosion process of scratched epoxy coated carbon steel. No significant reduction in $|Z|$ and no change in the passive film characteristics are observed when the $\%$ of $\mathrm{NaCl}$ in SPS is $0.05 \%$ due to the presence of sufficient concentration of inhibitive $\mathrm{OH}^{-}$ions. The inferences made in the present study points out that $0.05 \% \mathrm{NaCl}$ is the threshold level of chloride in SPS, above which the aggressive $\mathrm{Cl}^{-}$ions is likely to increase the corrosion rate of scratched epoxy coated carbon steel.

\section{Acknowledgement}

This work was supported by Council for Science, Technology and Innovation (CSTI), Cross-ministerial Strategic Innovation Promotion Program (SIP), “Infrastructure maintenance, renovation and management" (Funding agency: JST)

\section{References}

[1] F. Mansfeld, Models for the impedance behavior of protective coatings and cases of localized corrosion, Electrochim. Acta, 38 (1993) 1891- 1897

[2] G. W. Walter, A review of impedance plot methods used for corrosion performance analysis of painted metals, Corros Sci., 26 (1986) 681-703 
[3] I. Annergren, F. Zou, D. Thierry, Application of localised electrochemical techniques to study kinetics of initiation and propagation during pit growth, Electrochim. Acta, 44 (1999) 4383-4393

[4] G. Grundmeier, W. Schmidt, M. Stratmann, Corrosion protection by organic coatings: electrochemical mechanism and novel methods of investigation, Electrochim. Acta, 45 (2000) 2515-2533

[5] V. Vignal , H. Krawiec, O. Heintz, D. Mainy, Passive properties of lean duplex stainless steels after long-term ageing in air studied using EBSD, AES, XPS and local electrochemical impedance spectroscopy, Corros. Sci., 67 (2013) $109-117$

[6] J. B. Jorcin, E. Aragon, C. Merlatti , N. Pébère, Delaminated areas beneath organic coating: A local electrochemical impedance approach, Corros. Sci., 48 (2006) 1779-1790

[7] R.S. Lillard, J. Kruger, W.S. Tait, P.J. Moran, Using local electrochemical impedance spectroscopy to examine coating failure, Corrosion, 51, (1995) 251-259

[8] L. V. S. Philippe, G. W. Walter, and S. B. Lyon, Investigating localized degradation of organic coatings comparison of electrochemical impedance spectroscopy with local electrochemical impedance spectroscopy, J. Electrochem. Soc., 150 (2003) B111-B119

[9] F. Zou, D. Thierry, Localized electrochemical impedance spectroscopy for 
studying the degradation of organic coatings, Electrochim. Acta, 42 (1997) $3293-3301$

[10] C. Zhong, X. Tang, Y.F. Cheng, Corrosion of steel under the defected coating studied by localized electrochemical impedance spectroscopy, Electrochim. Acta, 53 (2008) 4740-4747

[11] V. M. W. Huang, S.L. Wu, M. E. Orazem, N. Pébère, B. Tribollet, V. Vivier, Local electrochemical impedance spectroscopy: A review and some recent developments, Electrochim. Acta, 56 (2011) 8048- 8057

[12] R. S. Lillard, P. J. Moran H. S. Isaacs, A novel method for generating quantitative local electrochemical impedance spectroscopy J. Electrochem. Soc., 139, (1992) 1007-1012

[13] G. K. Glass, N. R. Buenfeld, The presentation of the chloride threshold level for corrosion of steel in concrete, Corros. Sci., 39, (1997) 1001- 1013

[14] X. Shi, T. A. Nguyen, P. Kumar, Y. Liu, A phenomenological model for the chloride threshold of pitting corrosion of steel in simulated concrete pore solutions, Anti-Corros Method Mater., 58, (2011) 179-189

[15] U. Angst, B. Elsener, C. K. Larsen, O. Vennesland, Critical chloride content in reinforced concrete - A review, Cem. Concr. Res. 39 (2009) 1122-1138

[16] G. A. Zhang, Y. F. Cheng, Micro-electrochemical characterization of corrosion of welded X70 pipeline steel in near-neutral pH solution, Corros. Sci.,51 (2009) 1714-1724 
Revised version - corrections/modifications are highlighted

[17] G. Z. Meng, C. Zhang, Y. F. Cheng, Effects of corrosion product deposit on the subsequent cathodic and anodic reactions of X-70 steel in near-neutral pH solution, Corros. Sci., 50 (2008) 3116-3122

[18] M. Keddam, O. R. Mattos, and H. Takenouti, Reaction model for iron dissolution studied by electrode impedance I. Experimental results and reaction model, J. Electrochem. Soc. 128 (1981) 257- 266

[19] M. Saremi, E. Mahallati, A study on chloride-induced depassivation of mild steel in simulated concrete pore solution, Cem. Concr. Res., 32 (2002) $1915-1921$

[20] G. T. Burstein, D. H. Davies, The effects of anions on the behaviour of scratched iron electrodes in aqueous solutions, Corros. Sci., 20 (1980) $1143-1155$

[21] J. M. R. Génin, L. Dhouibi, Ph. Refait, M. Abdelmoula, E. Triki, Influence of phosphate on the corrosion products of iron in chloride-polluted concrete-simulating solutions : ferrihydrite vs green rust, Corrosion 58 (2002) $467-478$

[22] L. Dhouibi, Ph. Refait, E. Triki, J. M. R. Génin, Interactions between nitrites and $\mathrm{Fe}(\mathrm{II})$-containing phases during corrosion of iron in concrete-simulating electrolytes, Journal of Materials Science 41 (2006) 4928-4936

[23] T. Nishimura, H. Katayama, K. Noda, and T. Kodama, Electrochemical behavior of rust formed on carbon steel in a wet/dry environment containing 
Revised version - corrections/modifications are highlighted

chloride ions, Corrosion, 56 (2000) 935-941

[24] R. G. Du, R. G. Hu, R. S. Huang, C. J. Lin, In Situ Measurement of ClConcentrations and $\mathrm{Ph}$ at the Reinforcing Steel/Concrete Interface by Combination Sensors, Anal. Chem. 2006, 78, 3179-3185

[25] M. Moreno, W. Morris, M.G. Alvarez, G.S. Duff, Corrosion of reinforcing steel in simulated concrete pore solutions Effect of carbonation and chloride content, Corros. Sci., 46 (2004) 2681-2699

[26] W. J. McCarter, Øystein Vennesland, Review: Sensor systems for use in reinforced concrete structures, Construction and Building Materials 18 (2004) $351-358$

[27] W Morris, A Vico, M Vazquez, S.R de Sanchez, Corrosion of reinforcing steel evaluated by means of concrete resistivity measurements, 44 (2002) 81-99

[28] D. Trejo, P. J. Monteiro, Corrosion performance of conventional (ASTM A615) and low-alloy (ASTM A706) reinforcing bars embedded in concrete and exposed to chloride environments, Cem. Concr. Res. 35 (2005) 562-571

[29] D. Izquierdo, C. Alonso, C. Andrade, M. Castellote, Potentiostatic determination of chloride threshold values for rebar depassivation: Experimental and statistical study, Electrochim. Acta, 49 (2004) 2731-2739

[30] D. A. Koleva, K. van Breugel, J. H. W. de Wit, E. van Westing, N. Boshkov, A. L. A. Fraaij, Electrochemical behavior, microstructural analysis, and 
morphological observations in reinforced mortar subjected to chloride ingress, J. Electrochem. Soc., 154, (2007), E45-E56

[31] U. Angst, B. Elsener, C. K. Larsen, O. Vennesland, Chloride induced reinforcement corrosion: Rate limiting step of early pitting corrosion, Electrochim. Acta, 56 (2011) 5877- 5889

[32] C.Q.Ye, R.G. Hu, S.G. Dong, X.J. Zhang, R.Q. Hou, R.G. Du, C.J. Lin, J.S. Pan, EIS analysis on chloride-induced corrosion behavior of reinforcement steel in simulated carbonated concrete pore solutions, J. Electroanal. Chem., 688 (2013) 275-281

[33] K.K. Sagoe-Crentsil, F.P. Glasse, "Green rust", Iron solubility and the role of chloride in the corrosion of steel at high pH, Cem. Concr. Res. 23 (1993) $785-791$

[34] S. Grousset, F. Kergourlay, D. Neff, E. Foy, J.-L. Gallias, S. Reguer, P. Dillmann A. Noumow'e, In situ monitoring of corrosion processes by coupled micro-XRF/micro-XRD mapping to understand the degradation mechanisms of reinforcing bars in hydraulic binders from historic monuments, J. Anal. At. Spectrom, 30, 2015, 721-729

[35] E.Volpi, A.Olietti, M.Stefanoni, S.P. Trasatti, Electrochemical characterization of mild steel in alkaline solutions simulating concrete environment, J. Electroanaly.Chem.736 (2015) 38-46

[36] D. H. van der Weidje, E. P. M. van Westing, and J. W. H. der Wit, EIS 
measurements on artificial blisters in organic coatings, Electrochim. Acta, 41, (1996) 1103-1107

[37] S.M. Cambier, D. Verreault, and G.S. Frankel, Raman investigation of anodic undermining of coated steel during environmental exposure, Corrosion, 70, $2014,1219-1229$

[38] T. Nguyen, J. W. Martin, Modes and mechanisms for the degradation of fusion-bonded epoxy-coated steel in a marine concrete environment, JCT Research, 1, 2004, 81-92

\section{Figure captions}

Fig. 1 The schematic of the electrode installation and experimental set-up of LEIS

Fig. 2 OCP-time curves of scratched epoxy coated carbon steel in SPS containing varying $\% \mathrm{Cl}^{-}$ions

Fig. 3 LEIS Nyquist plots of scratched epoxy coated carbon steel in SPS containing varying $\% \mathrm{Cl}^{-}$ions at their respective open circuit potentials: (a) Nyquist plots, (b) enlarged Fig of 0 and $0.05 \% \mathrm{Cl}$, and (c) enlarged Fig of 1 and $3 \% \mathrm{Cl}$

Fig. 4 Bode impedance (a) and Bode phase angle (b) plots of scratched epoxy coated carbon steel in SPS containing varying $\% \mathrm{Cl}^{-}$ions at their respective open circuit potentials

Fig. 5 Electrochemical parameters derived from fitting the LEIS data of scratched epoxy 
coated carbon steel in SPS containing varying $\% \mathrm{Cl}^{-}$ions at their respective open circuit potentials.

Fig. 6 The 3D LEIS maps and the corresponding 2D maps measured over a scanning area of $7 \mathrm{~mm} \times 1 \mathrm{~mm}$ (x-y scale) over the scratched epoxy coated carbon steel in SPS containing varying $\%$ of $\mathrm{Cl}^{-}$ions: $(\mathrm{a}, \mathrm{f}) 0 \% \mathrm{Cl}$; (b, g) $0.05 \% \mathrm{Cl}$; (c, h) $0.5 \% \mathrm{Cl}$; (d, i) $1 \%$ $\mathrm{Cl}$; (e, j) $3 \% \mathrm{Cl}$. Scale: $7 \mathrm{~mm} \times 1 \mathrm{~mm}$ in $\mathrm{x}$ and $\mathrm{y}$ directions, vertical direction is $|\mathrm{Z}|$

Fig. 7 (a) LEIS line profiles, (b) Impedance, $|\mathrm{Z}|_{10 \mathrm{~Hz}}$ at L zone, recorded over scratched epoxy coated carbon steel in SPS containing varying $\% \mathrm{Cl}^{-}$ions.

Fig. 8 A pictorial model is proposed to explain the corrosion mechanism of scratched epoxy coated carbon steel in SPS containing varying $\%$ of $\mathrm{Cl}^{-}$ions 


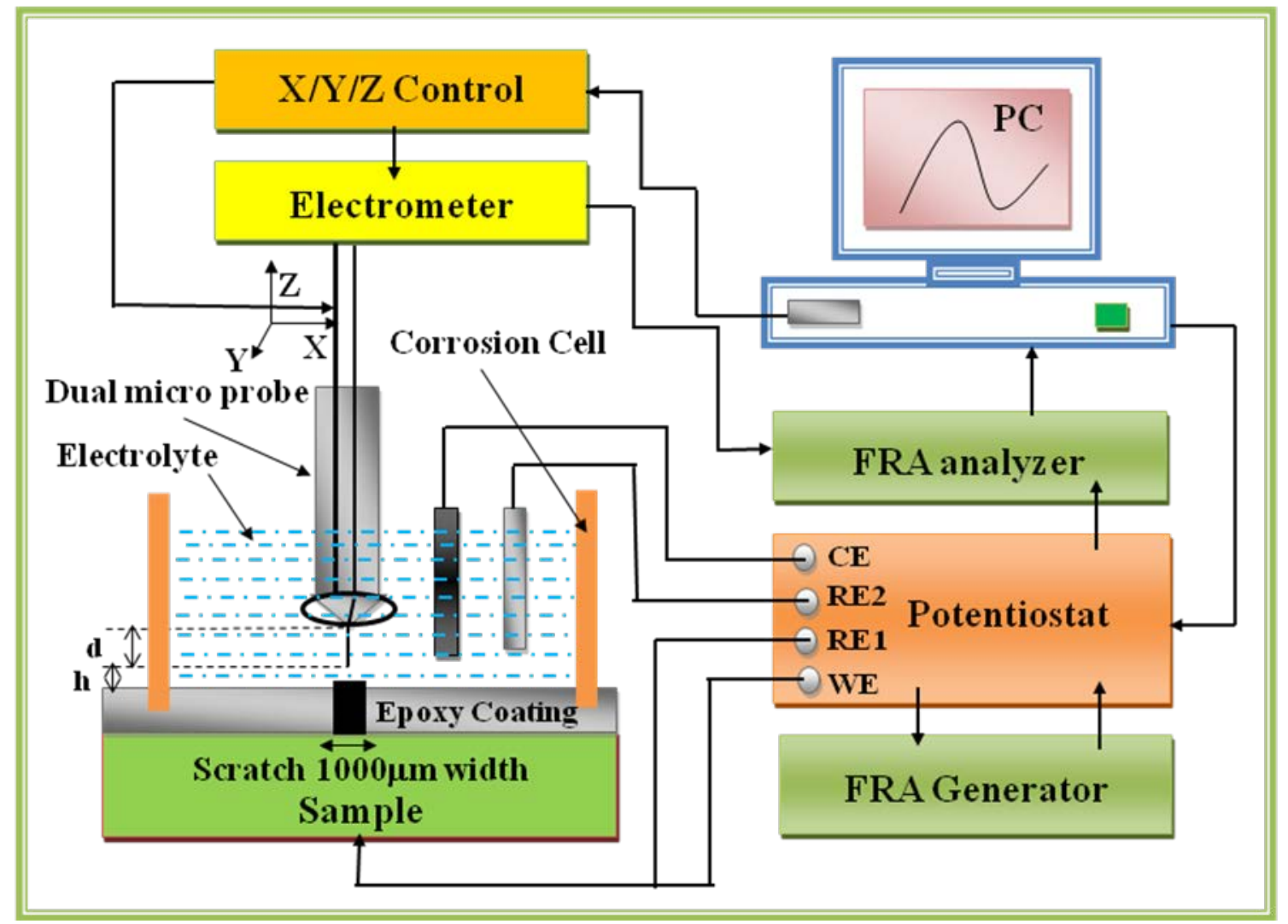

Figure. 1 


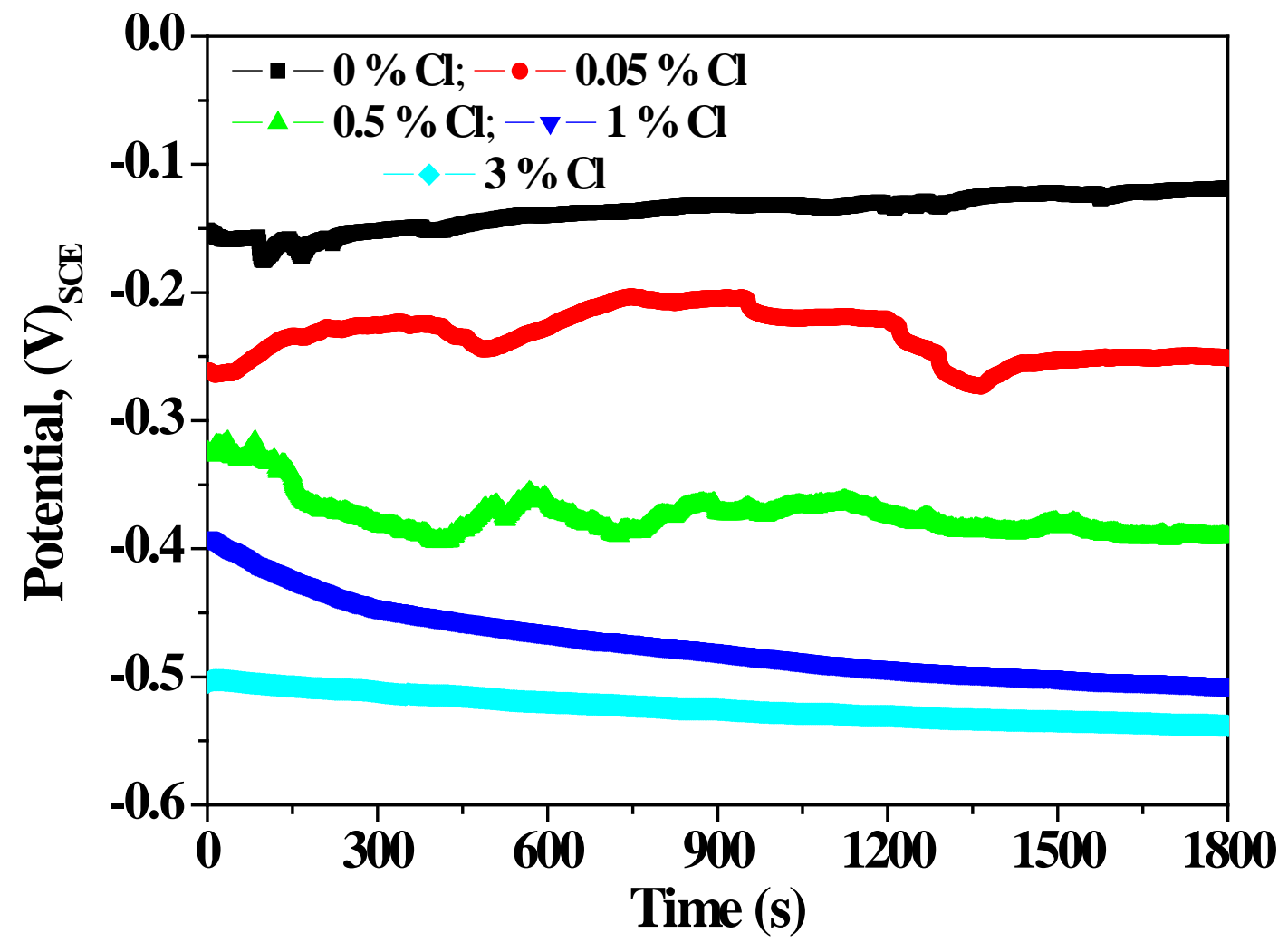

Figure. 2 


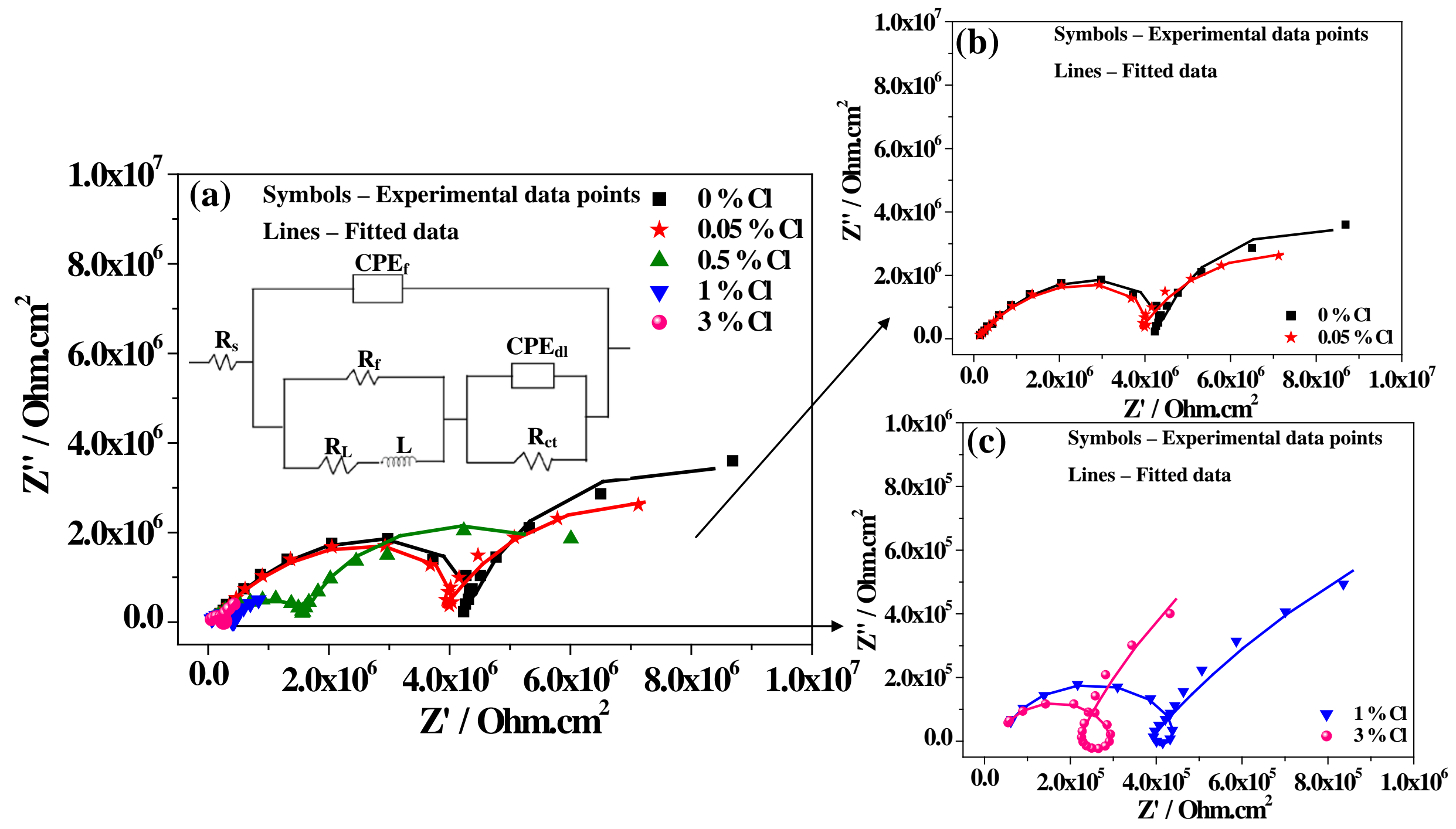

Figure.3 

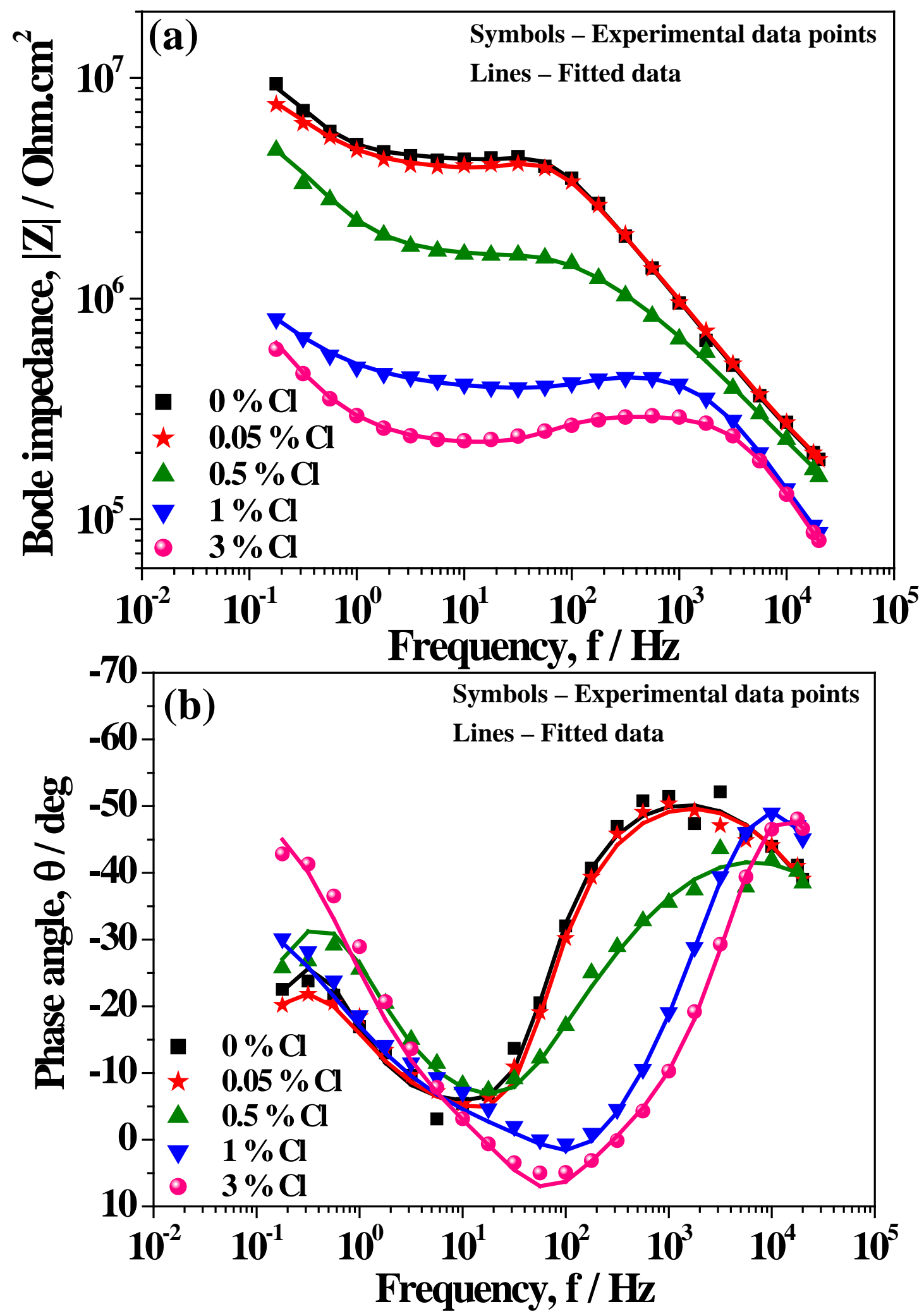

Figure. 4 

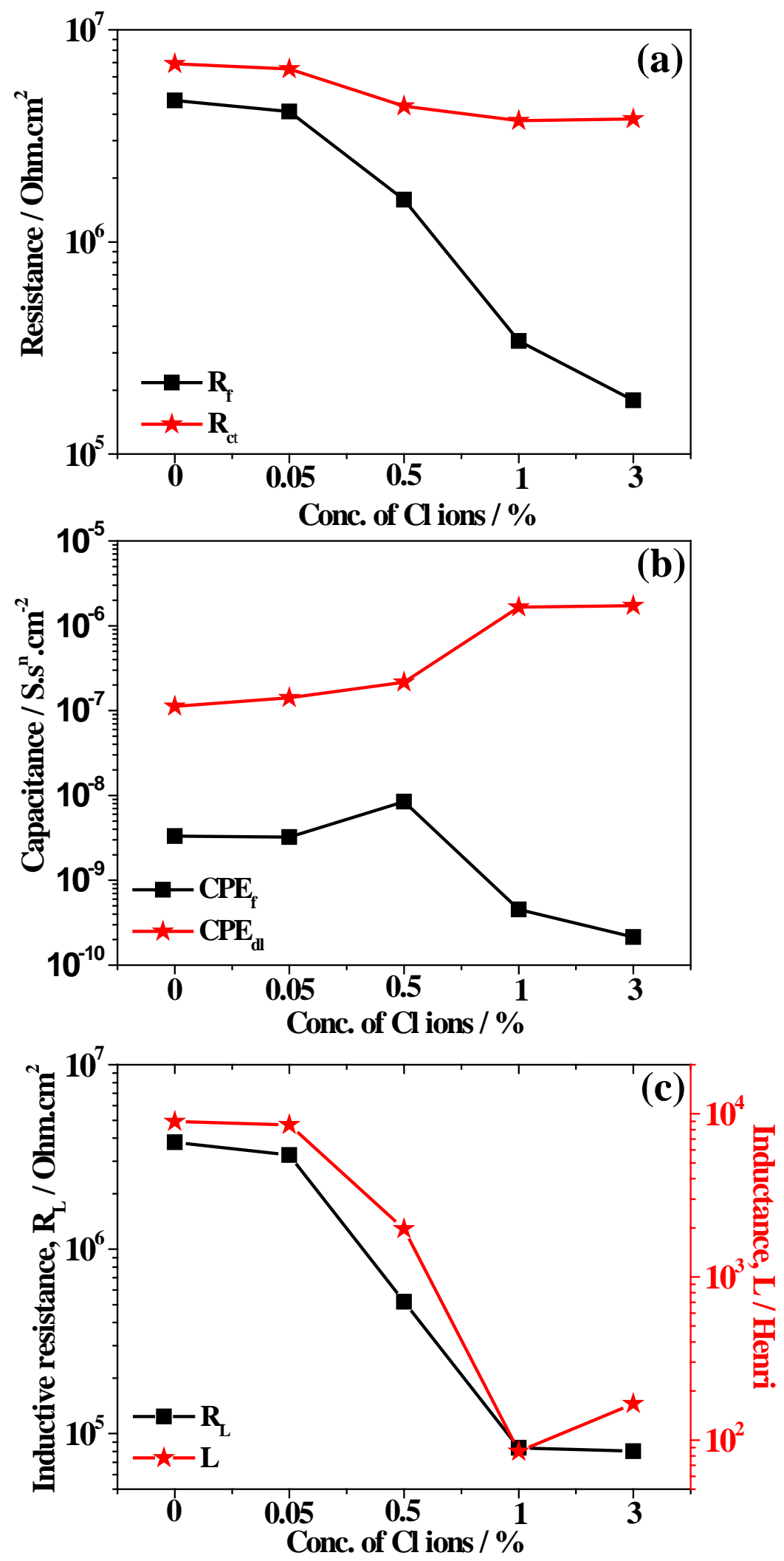

Figure. 5 


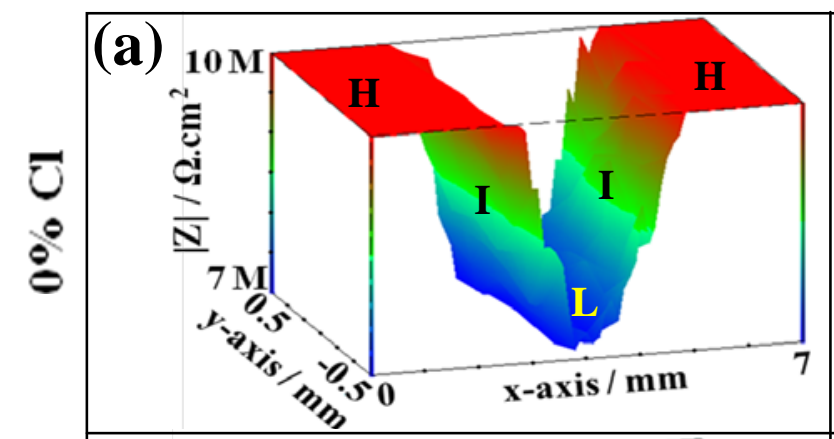

(f)
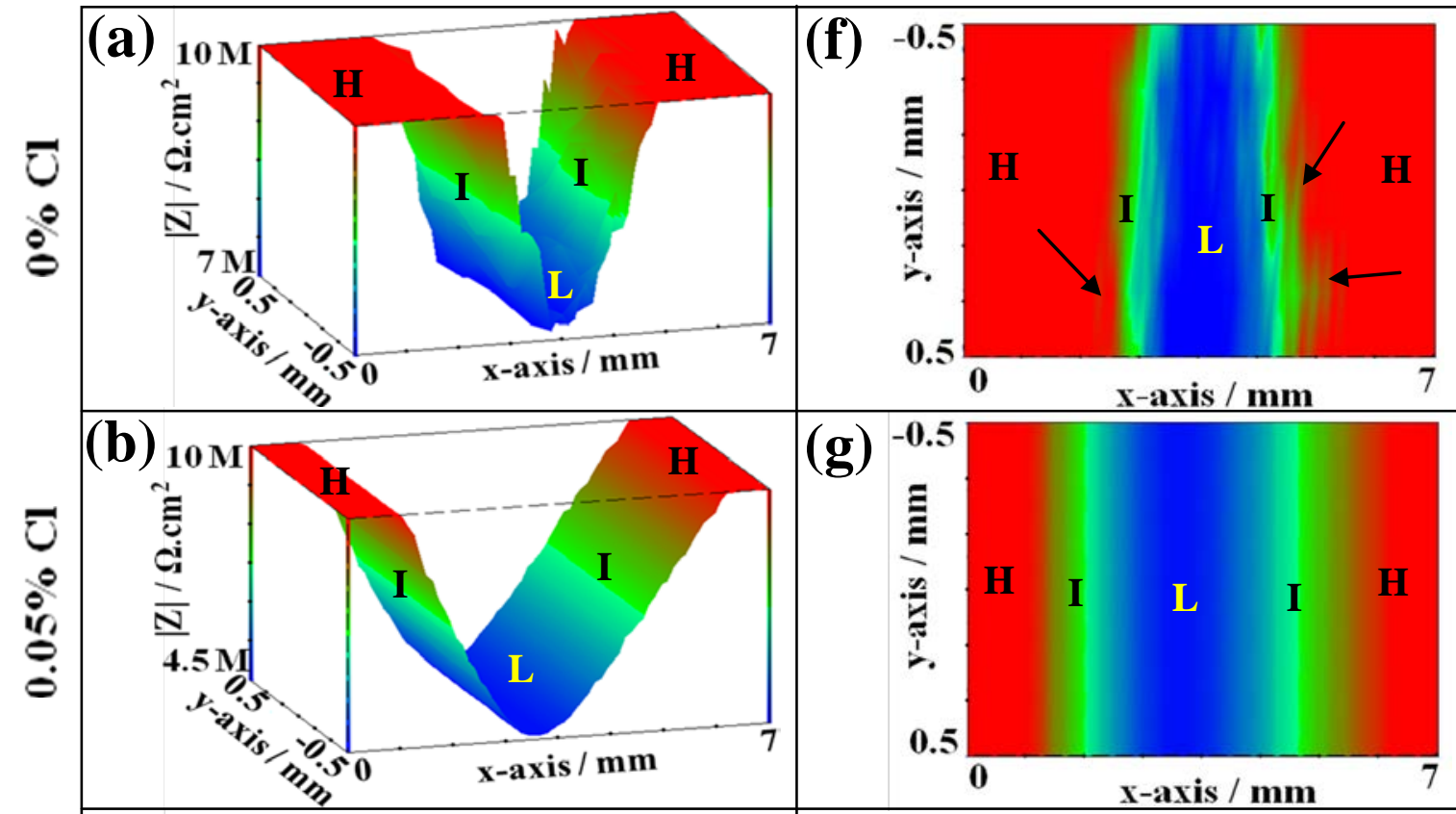

(g)
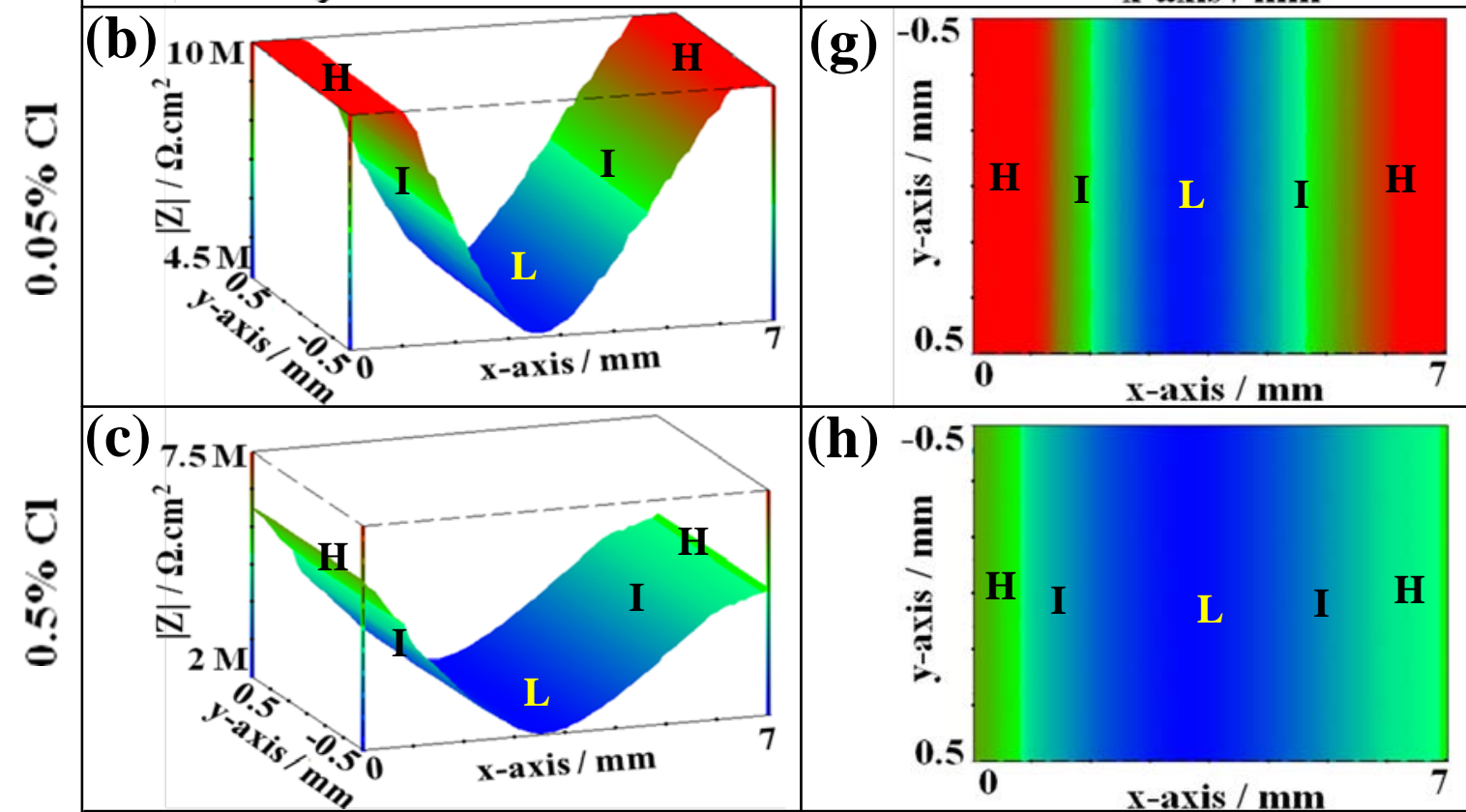

(h)
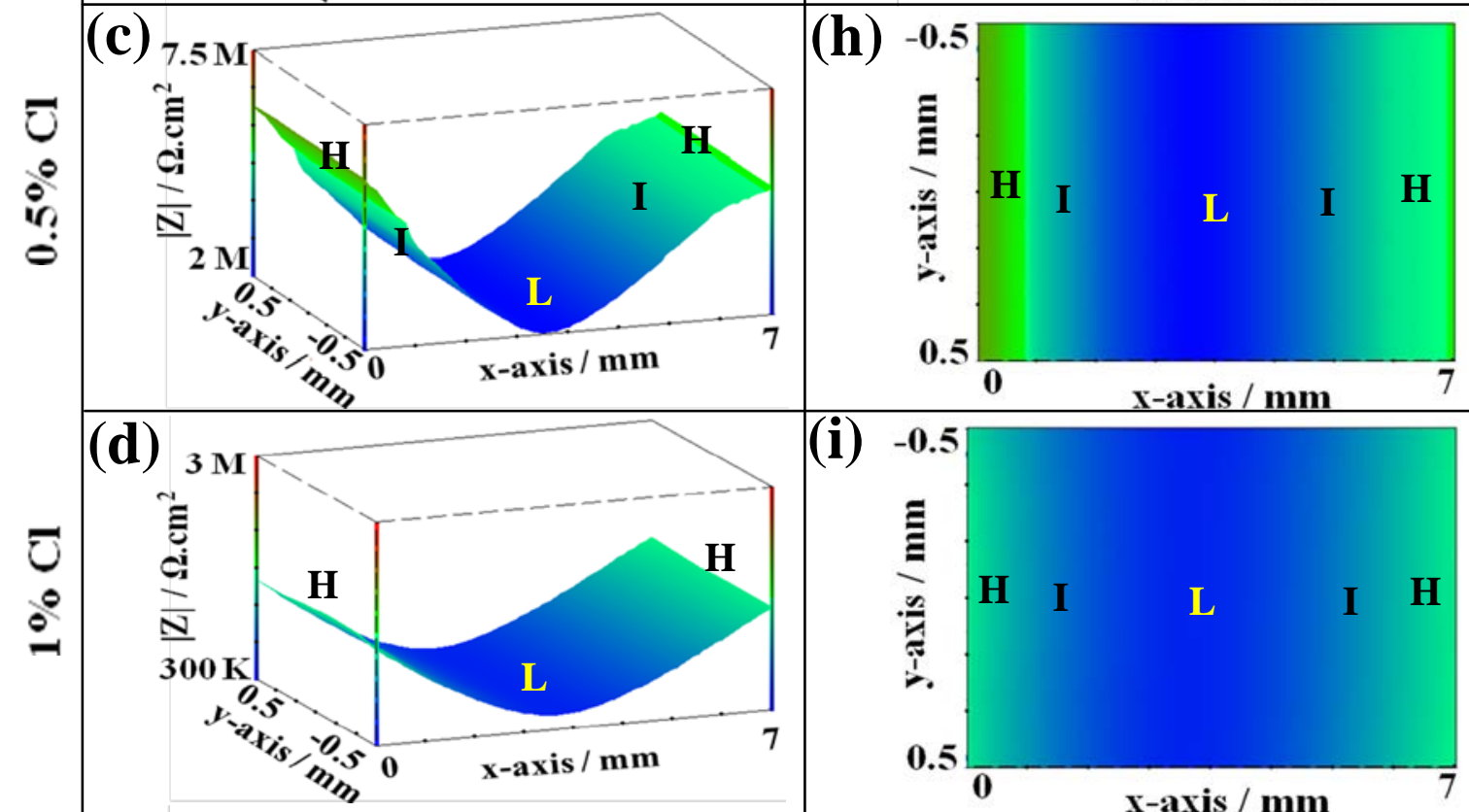

(i)
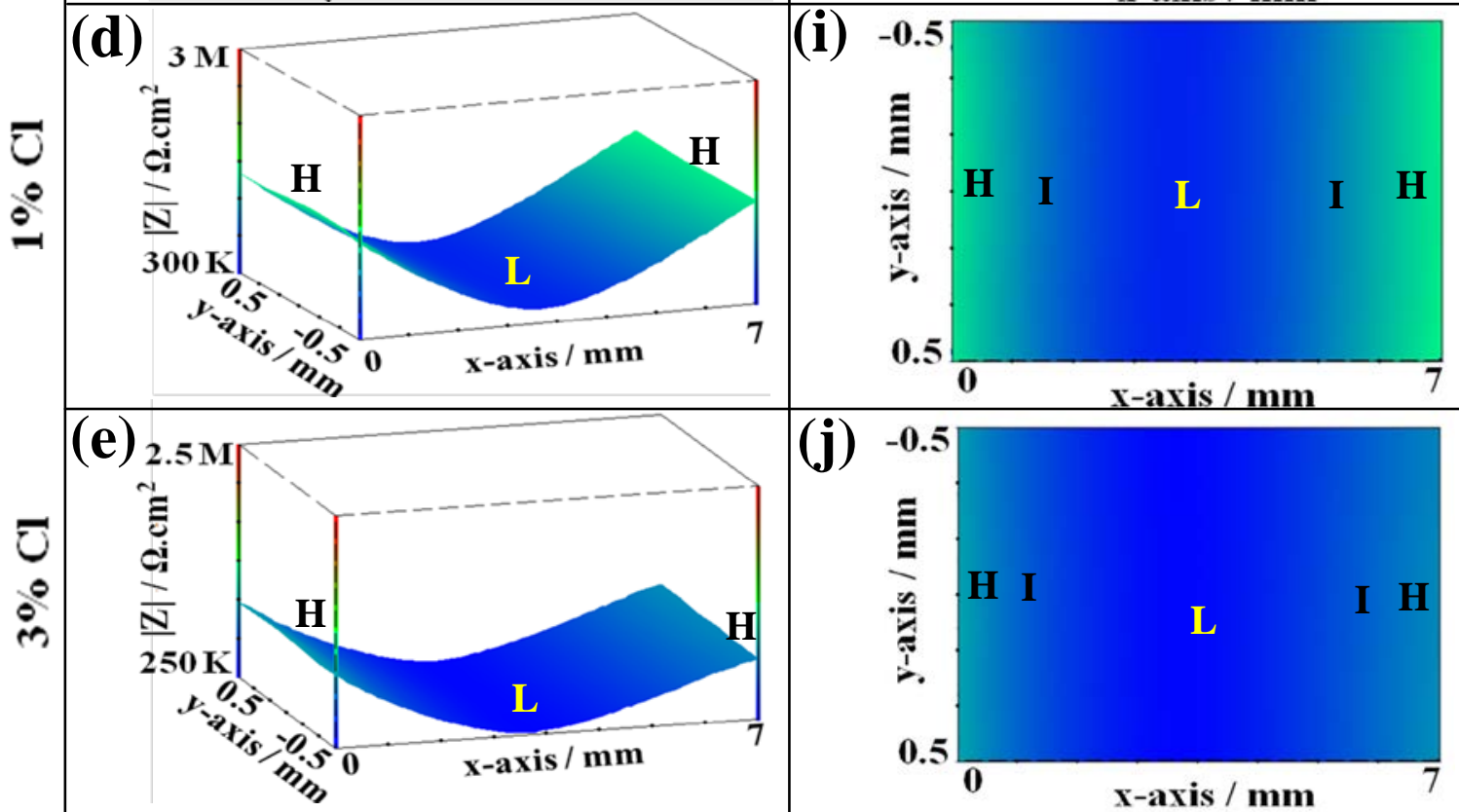

(j)

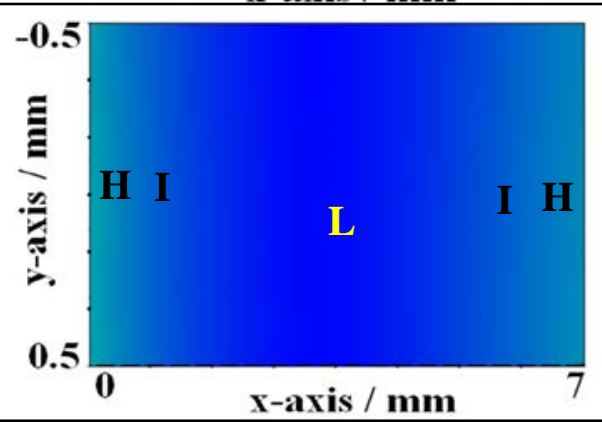

Figure. 6 

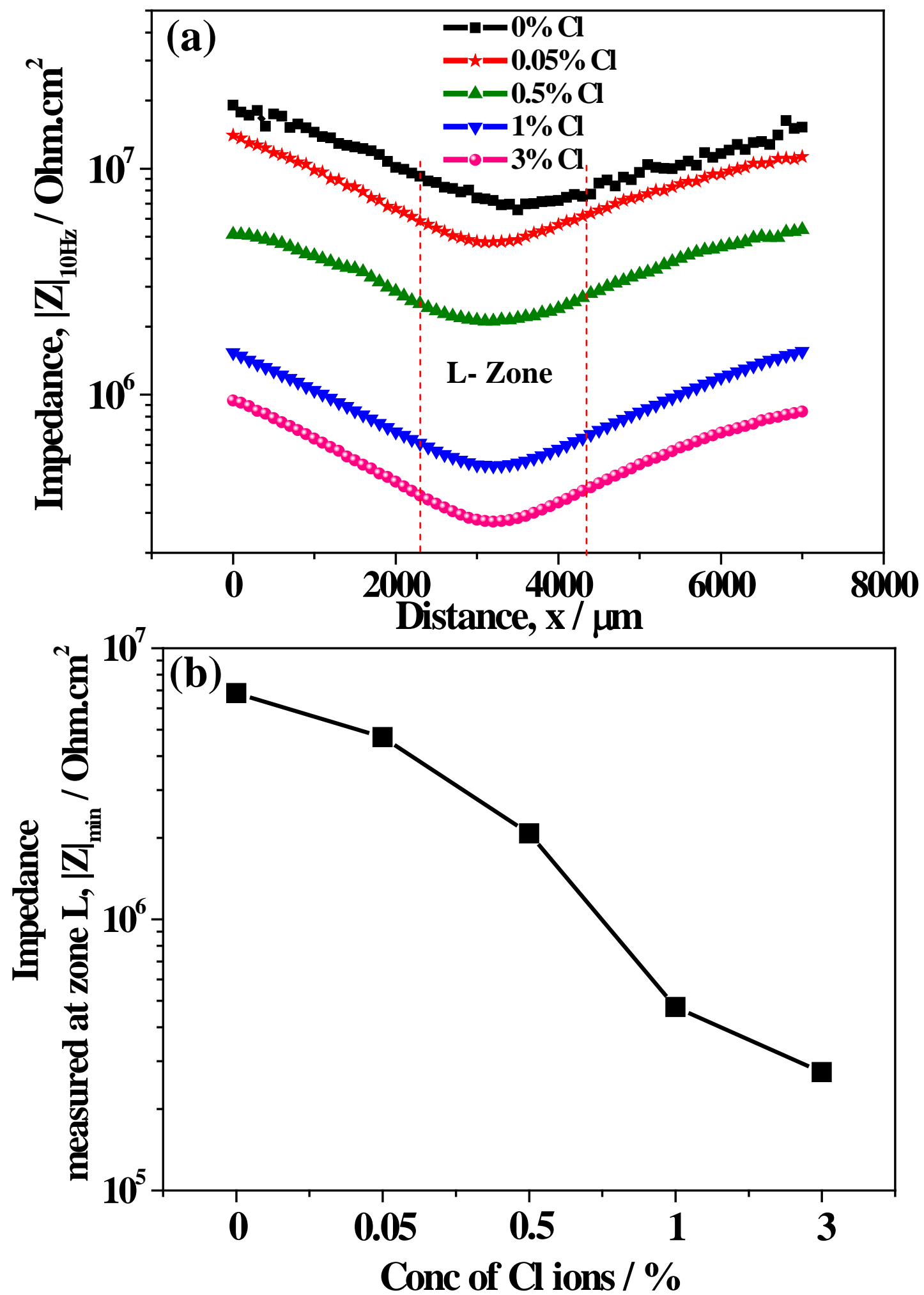

Figure. 7 


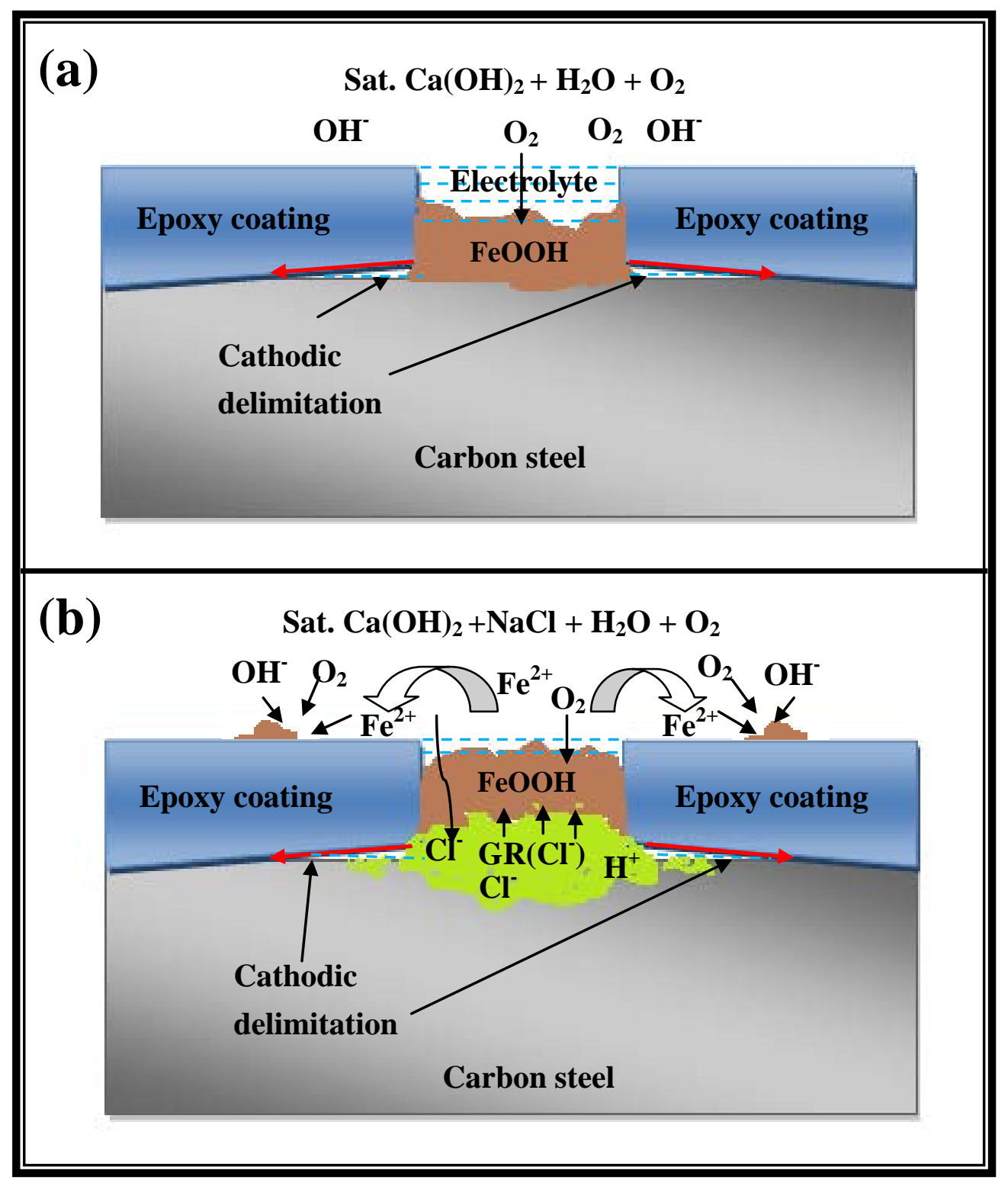

Figure. 8 


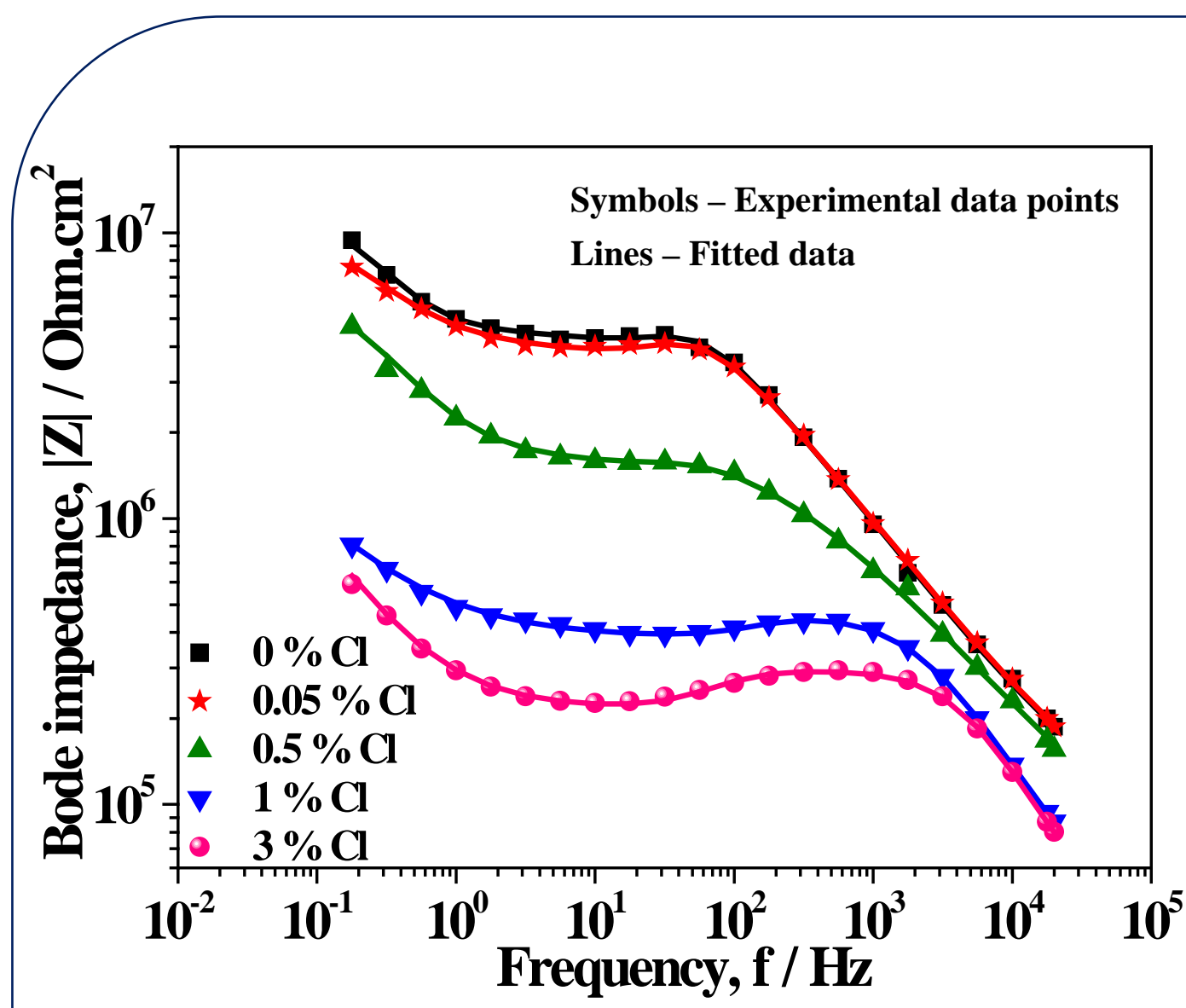

LEIS Bode impedance plots of scratched epoxy coated carbon steel in simulated pore solution containing varying $\% \mathrm{of}^{-}$ions at their respective open circuit potentials
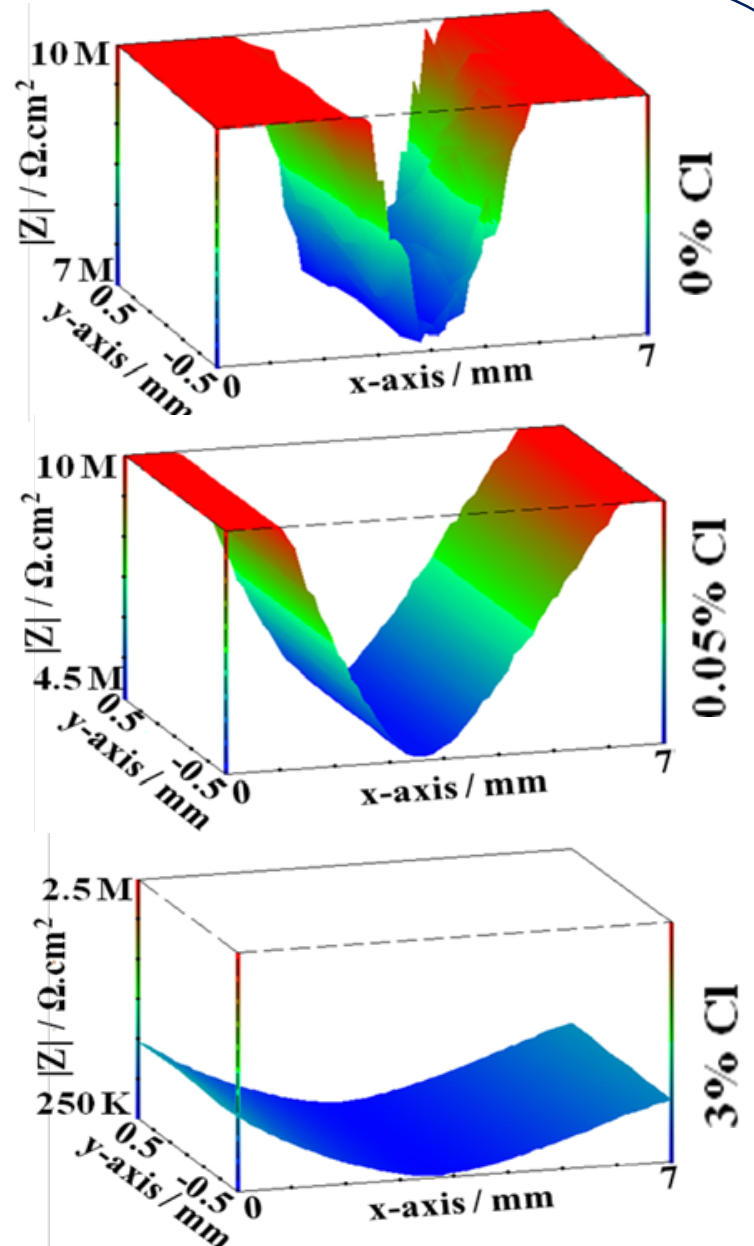

LEIS 3D mapping: Scale: $7 \mathrm{~mm} \times 1 \mathrm{~mm}$ in $x$ and $y$ directions, vertical direction is $|\mathrm{Z}|$ 